\title{
Cost of Illness in Patients with Duchenne Muscular Dystrophy in Portugal: The COIDUCH Study
}

\author{
Pedro Labisa ${ }^{1}$ - Valeska Andreozzi ${ }^{1}$ - Melina Mota ${ }^{1} \cdot$ Susana Monteiro $^{1} \cdot$ Rita Alves $^{1}$. João Almeida ${ }^{1}$. \\ Björn Vandewalle ${ }^{1} \cdot$ Jorge Felix $^{1} \cdot$ Katharina Buesch $^{2} \cdot$ Hugo Canhão $^{3} \cdot$ Igor Beitia Ortiz de Zarate ${ }^{3}$
}

Accepted: 5 September 2021 / Published online: 3 October 2021

(c) The Author(s) 2021

\begin{abstract}
Objective The aim of this study was to estimate the cost of illness (COI) of Duchenne muscular dystrophy (DMD) and its relation to disease progression, using age as a proxy, and according to the ambulatory status of patients.

Methods We conducted a cross-sectional study of patients diagnosed with DMD identified through the Portuguese Neuromuscular Patients Association (APN). Data regarding patient and caregiver demographics, patient health status, resource utilization and cost, and informal care were collected using a custom semistructured questionnaire. Labor productivity and absenteeism losses were captured using the Work Productivity and Activity Impairment questionnaire. Costs were valued using a societal perspective.

Results A total of 46 patient-caregiver pairs were included, of which eight of the patients were ambulant and 38 were nonambulant. Age had a decreasing effect on COI, independent of the patient's disease stage. Annualized lifetime costs were at their highest in nonambulant patients around the mean age of loss of ambulation (10 years of age). The mean per patient stage-specific costs (year 2019 values) of DMD were estimated at $€ 48,991$ in the nonambulant stage and $€ 19,993$ in the ambulant stage. Direct nonmedical costs were the main cost drivers, followed by indirect costs.

Conclusions Our results indicate a close relation between overall disease costs and disease progression. DMD is associated with a substantial economic burden, which appears to be larger around the time ambulation is lost (10 years of age). The availability of new therapeutic options that delay disease progression, especially loss of ambulation, may prove to be highly beneficial for not only patients with DMD but also their families and society.
\end{abstract}

\section{Background}

Duchenne muscular dystrophy (DMD) is a rare neuromuscular X-linked disorder that primarily affects males and is caused by mutations in the dystrophin gene. It has an estimated prevalence of 7.1 (95\% confidence interval [CI] 5.0-10.1) cases per 100,000 males and a birth prevalence of 19.8 (95\% CI 16.6-23.6) cases per 100,000 live male births $[1,2]$. The lack of functional dystrophin causes the progressive degeneration of muscle fibers, resulting in increased muscle atrophy and weakness. Symptoms such as delayed walking and difficulty running and climbing stairs

Valeska Andreozzi

valeska.andreozzi@exigoconsultores.com

Exigo Consultores, Lisbon, Portugal

2 PTC Therapeutics International, Steinhausen, Switzerland

3 PTC Therapeutics, Sintra, Portugal

\section{Key Points for Decision Makers}

Duchenne muscular dystrophy is associated with a substantial economic burden that appears to increase with disease progression, most importantly loss of ambulation.

In Portugal, annualized costs in the nonambulant stage were more than double those in the ambulatory stage.

Lifetime annualized costs were at their highest among nonambulant patients around the time ambulation was lost (10 years of age).

New therapeutic options that delay disease progression, especially loss of ambulation, may be highly beneficial for not only patients but also their families and society as a whole. 
start manifesting before the age of 5 years. Disease severity increases as patients age [3], eventually leading to the loss of ambulation around the early teenage years, followed by the need for ventilation support and eventually death before 40 years of age [4]. The natural history of the disease has evolved in recent years as the use of physiotherapy and glucocorticoids and the advent of drugs targeting the underlying cause of the disease in some specific patient subpopulations have shown efficacy in delaying disease progression $[2,5]$.

DMD is associated with a considerable socioeconomic burden because of the high demand for healthcare and nonhealthcare resources as well as the substantial caregiver burden, both in terms of informal care hours and reduced work productivity [6-8]. Evidence further suggests that the economic burden is influenced by disease progression, with patients in more advanced, nonambulant stages incurring greater annual costs than ambulant patients $[6,8]$. Nevertheless, given the rare nature of the disease, comprehensive cost data and its relation to disease progression across different geographical settings remain sparse. COIDUCH (Cost-ofIllness study in patients with Duchenne muscular dystrophy) aimed to assess the patient and societal burden of DMD in Portugal. In this paper, we report upon the cost of illness (COI) and its relation to disease progression, based on age as a proxy, and according to the ambulatory status of patients.

\section{Methods}

\subsection{Study Design and Data Collection}

This was a cross-sectional study of patients diagnosed with DMD identified through the Portuguese Neuromuscular Patients Association (APN). All patients and caregivers were informed of the study objectives and data confidentiality. Patients receiving experimental drugs or placebo in randomized controlled trials were excluded.

After participants provided written informed consent, a face-to-face interview was conducted by trained interviewers. The fieldwork was carried out in June and August 2019. Primary caregivers and patients with DMD were asked to answer a customized questionnaire, developed in collaboration with the APN to ensure that questions were adequate and correctly understood. The questionnaire included questions regarding caregiver and patient demographics, patient health status, DMD-related healthcare and nonhealthcare resource utilization and costs, and DMD-related household expenses. Caregiver absenteeism and presenteeism due to patient DMD was collected using the Work Productivity and Activity Impairment (WPAI) questionnaire [9] .

Data were collected retrospectively with prespecified recall periods. To minimize recall bias, most questions regarding resource utilization covered the previous 6 months. The recall period was extended to the patient's lifetime when pertaining to items with one-off acquisition costs (such as devices, DMD-related household expenses, and surgeries) that would be underreported if restricted to the 6-month recall period. Data collected from the WPAI questionnaire referred to the previous 7 days.

\subsection{Assessment of Cost of Illness}

Costs were valued using a societal perspective and reported in $€$ standardized to year 2019 values using the consumer price index for Portugal [10]. Direct medical and nonmedical costs, the majority of which had a recall period of 6 months, were annualized assuming constant use of resources. Oneoff acquisition costs had a more extensive recall period and were estimated as cumulative per-patient mean costs during an extended time period. Unit costs for both medical and nonmedical goods and services were obtained, preferably from caregivers and/or patients or alternatively from national databases, legislation, and wholesalers [11-15].

Informal care costs were valued according to the proxy good method [16], in which the time spent on informal care is valued according to the price of a close market substitute. As a conservative estimate, the number of care hours was valued at a market price of $€ 5 / \mathrm{h}$, which is the average wage paid to formal caregivers of patients with DMD according to the APN. To avoid double counting of time, primary caregivers were asked about the average number of daily hours actively dedicated to informal care, discounting working hours (if working) and/or leisure time. If the caregiver was not working because of DMD, costs were calculated according to the number of informal care hours reported minus the national mean number of daily working hours, adjusted for sex of the caregiver.

Indirect costs due to absenteeism and changes in working situation or presenteeism of the primary caregiver were estimated using the human capital approach [17], in which the average gross wage of the individual is considered a good proxy for the loss of labor productivity. Each hour of lost productivity was valued according to the Portuguese average gross wage $[18,19]$, assuming the national average working hours in 2017, both adjusted for sex [20]. The formula used in the calculation is described in the electronic supplementary material.

Two analyses were conducted. The first estimated the cost of illness of DMD according to ambulatory status. For the ambulant stage, all costs of patients still ambulant at the date of interview were considered. Conversely, costs in the nonambulant stage consisted of all annualized costs reported during the past 6 months by nonambulant patients and all annualized costs of one-off resources incurred exclusively 
during the nonambulant period. One-off acquisition costs were annualized as the cumulative per-patient mean costs divided by the time period between ambulation loss and the interview.

The second analysis aimed to determine the annualized lifetime cost for each patient and included all costs incurred during their disease trajectory from diagnosis to the moment of the interview.

\subsection{Statistical Analysis}

Collected data were summarized descriptively according to ambulatory stage, using summary statistics such as mean and standard deviation for continuous variables and absolute and relative frequencies for categorical variables.

The relationship between the annualized lifetime cost and disease progression was analyzed using patient age as proxy for disease progression, given its close relation with motor and cardiovascular function deterioration [21-27]. In this analysis, the patient's age at the date of interview was estimated with a flexible approach using a generalized additive model. To address the skewed distribution of costs, a gamma distribution with a logarithmic link function was used, whereas a possible nonlinear effect of age was addressed adopting a thin plate regression spline [28]. To control for confounding effects, the model was adjusted for ambulatory status at the date of interview. This flexible modelling approach allowed the estimation of hidden patterns of the behavior of the annualized lifetime cost as a function of disease progression, not restricted to estimating a linear or multiplicative effect.

All statistical analyses were performed using the statistical software $\mathrm{R}^{\circledR}$ [29].

\section{Results}

A total of 46 patient-caregiver pairs provided informed consent and completed the questionnaires. All patients were male, with a mean age of 8 and 21 years in the ambulant ( $n$ $=8)$ and nonambulant $(n=38)$ groups, respectively. Loss of ambulation occurred at a mean age of 10 years, followed by use of assisted ventilation at a mean age of 17 years (Table 1).

The majority of caregivers were mothers to the patients with DMD. A high proportion of caregivers of nonambulant patients were not working and also reported a high mean number of hours dedicated to informal care (Table 1).

\subsection{Estimated Cost of Illness}

All DMD-related stage-specific costs are presented in Table 2, divided according to the major cost categories. The mean per patient total annual cost of DMD was estimated at $€ 48,991$ in the nonambulant stage compared with $€ 19,993$ in the ambulant stage. Direct nonmedical costs were the main driver of DMD costs (nonambulant $61 \%$; ambulant $60 \%$ of total costs), followed by indirect costs (nonambulant $21 \%$; ambulant $22 \%$ of total costs) and by direct medical costs (nonambulant 19\%; ambulant $19 \%$ of total costs).

Mean direct annual medical costs were two times higher in the nonambulant stage than in the ambulant stage ( $€ 9063$ vs. 3708). Ambulant-stage direct medical costs were primarily driven by physician and/or other health professional visits $(€ 3126)$. In the nonambulant stage, the two main cost drivers were physician and/or other health professional visits (€3157) and medical devices (€3582) (Table 2).

Mean annual direct nonmedical costs during the nonambulant stage were over twice those of the ambulant stage ( $€ 29,717$ vs. 11,890 ), with informal care costs being the main cost driver (nonambulant $€ 20,772$; ambulant $€ 9996$ ) (Table 2).

Indirect costs of primary caregivers from loss of productivity due to DMD were more than three times higher for the nonambulant group than for the ambulant group $(€ 10,211$ vs. 4395) (Table 2).

\subsection{Estimated Lifetime Cost of IIIness}

Figure 1 shows a scatterplot of the patient's annualized lifetime costs and their respective age, stratified according to their ambulatory stage at the time of the interview. Age is used here as a proxy of disease progression. The average of 10 years of age for loss of ambulation is corroborated in the plot.

The generalized additive model estimated a decreasing effect of age independent of the patient's disease stage (Fig. 1). Annualized lifetime costs started at $€ 25,000$ and slightly declined as age increased for the ambulant patients, with age ranging from 2 to 10 years. Although nonambulant patients also presented a decreasing annualized lifetime cost, the model fitted suggested a greater disease burden around the mean age of loss of ambulation followed by a slightly linear decrease until around 20 years of age, when the cost stabilized at around $€ 50,000$ per year. 
Table 1 Characteristics of the study participants by ambulatory status

\begin{tabular}{lll}
\hline Characteristics & Ambulant patients $(n=8)$ & Nonambulant patients $(n=38)$ \\
\hline Patients & & \\
Sex, male & $8(100)$ & $38(100)$ \\
Age, years & $7.9 \pm 2.8(2.2 ; 10.4)$ & $21.3 \pm 7.0(7.8 ; 38.7)$ \\
$\quad$ At interview & $3.4 \pm 2.1(0.8 ; 6.1)$ & $4.6 \pm 2.4(0.2 ; 9.6)$ \\
At diagnosis & - & $9.7 \pm 2.3(5.0 ; 17.0)$ \\
At loss of ambulation & - & $16.9 \pm 4.3(7.0 ; 25.0)$ \\
At start of assisted ventilation & $4(50.0)$ & $7(18.4)$ \\
Presence of nonsense mutation & & \\
Caregivers & $7(88)$ & $32(84)$ \\
Sex, female & $40.4 \pm 10.0(25 ; 57.6)$ & $50.5 \pm 8.9(33.9 ; 63.5)$ \\
Age at interview, years & & $36(95)$ \\
Relationship to the patient & $8(100)$ & $2(5)$ \\
Parent & - & $28(74)$ \\
$\quad$ Other family member & $3(38)$ & $26(68)$ \\
Employment status, not working & $2(25)$ & $22(58)$ \\
Altered employment status due to DMD & $1(13)$ & $4(11)$ \\
Stopped working & $1(13)$ & $14.0 \pm 5.1(3.5 ; 22.0)$ \\
Reduced working hours & $6.1 \pm 2.0(3.5 ; 9.5)$ & \\
Daily hours dedicated to informal care & &
\end{tabular}

Data presented as $n(\%)$, mean \pm standard deviation, or (minimum; maximum) unless otherwise specified DMD Duchenne muscular dystrophy

${ }^{a}$ Only primary caregiver data were included

\section{Discussion}

To our knowledge, this is the first study to analyze the COI of DMD in Portugal according to patients' ambulatory status.

Our results point to a close relation between overall disease costs and disease progression. Mean annual costs in the nonambulant stage were more than double those in the ambulatory stage ( $€ 48,991$ vs. 19,993 , respectively). Direct nonmedical costs were the main component of annual costs in both stages and were primarily driven by informal care costs (nonambulant $42 \%$; ambulant $50 \%$ of total cost). As DMD progresses and mobility decreases, caregivers try to compensate for the greater need for supervision and support by allocating a larger proportion of their day to informal care. This is consistent with what has been reported in other publications [6, 7]. Surprisingly, costs related to nonmedical services such as formal caregivers, social institutions, and transport services remained similar in both stages (nonambulant $€ 1615$; ambulant $€ 1894$ ). This suggests that, even when confronted with a greater need for care, families continue to rely primarily on informal care rather than using third-party services that could potentially help reduce caregiver burden.
The substantial caregiver burden also had important impacts on indirect costs because of loss of productivity, which were almost three times higher in the nonambulant stage than in the ambulant stage ( $€ 10,211$ vs. 4395 , respectively). Around two-thirds (68\%) of caregivers of nonambulant patients reported having altered their employment status because of DMD, either stopping work completely $(58 \%)$ or reducing their work hours $(11 \%)$.

Direct medical costs were the least influential cost driver and resulted primarily from visits to physicians and/ or other health professionals (nonambulant 6\%; ambulant $16 \%$ of total costs) and medical device costs (nonambulant $7 \%$; ambulant $2 \%$ of total costs). Hospital care costs and nutrition support and other health products, while barely present during the ambulant stage, reached an annual mean of $€ 889$ during the nonambulant stage. This was also the case for medical device costs, resulting from the high acquisition and maintenance costs of wheelchairs and respiratory assistance devices during the nonambulant stage. Treatment costs remained fairly low in both stages $(<1 \%$ of total annual costs), which was expected because, despite some recent therapeutic developments, standard of care continues to rely predominantly on the use of low-cost treatment options such as corticosteroids. 
Table 2 Mean per-patient annual cost of Duchenne muscular dystrophy by ambulatory stage

\begin{tabular}{|c|c|c|c|c|}
\hline \multirow[t]{2}{*}{ Cost category } & \multicolumn{2}{|l|}{ Ambulant stage } & \multicolumn{2}{|c|}{ Nonambulant stage } \\
\hline & Annual cost & $\begin{array}{l}\text { Proportion } \\
\text { (\%) of total } \\
\text { COI }\end{array}$ & Annual cost & $\begin{array}{l}\text { Proportion } \\
\text { (\%) of tota } \\
\text { COI }\end{array}$ \\
\hline Direct medical cost & $3708 \pm 1561$ & 19 & $9063 \pm 5416$ & 19 \\
\hline Hospital care ${ }^{\mathrm{a}}$ & $25 \pm 70$ & $<1$ & $889 \pm 1241$ & 2 \\
\hline Physician and/or other health professional visits (including rehabilitation) & $3126 \pm 1195$ & 16 & $3157 \pm 2486$ & 6 \\
\hline Tests and diagnostics & $69 \pm 61$ & $<1$ & $214 \pm 292$ & $<1$ \\
\hline Drug treatments ${ }^{\mathrm{b}}$ & $175 \pm 150$ & $<1$ & $333 \pm 362$ & $<1$ \\
\hline Nutrition support and other health products (supplements and cosmetics) & $7 \pm 21$ & $<1$ & $889 \pm 2889$ & 2 \\
\hline Medical devices & $305 \pm 403$ & 2 & $3582 \pm 2497$ & 7 \\
\hline Direct nonmedical costs & $11,890 \pm 5547$ & 60 & $29,717 \pm 14,374$ & 61 \\
\hline House and/or car adaptations & & - & $7329 \pm 15,257$ & 15 \\
\hline Nonmedical services ${ }^{c}$ & $1894 \pm 3298$ & 10 & $1615 \pm 2226$ & 3 \\
\hline Informal care & $9996 \pm 3711$ & 50 & $20,772 \pm 9081$ & 42 \\
\hline Indirect costs & $4395 \pm 6415$ & 22 & $10,211 \pm 6352$ & 21 \\
\hline Absenteeism and/or changes in working situation & $2824 \pm 4978$ & 14 & $9292 \pm 6947$ & 19 \\
\hline Presenteeism & $1572 \pm 3506$ & 8 & $919 \pm 1963$ & 2 \\
\hline Total cost of illness & $19,993 \pm 5944$ & & $48,991 \pm 15,394$ & \\
\hline
\end{tabular}

Data are presented in $€$, year 2019 values, as mean \pm standard deviation unless otherwise indicated. Because of rounding, percentages might not add up to exactly 100

COI cost of illness

${ }^{a}$ Includes hospitalization, emergency visits, and surgeries

${ }^{\mathrm{b}}$ Includes all disease-related drug costs, except costs for ataluren (Translarna ${ }^{\circledR}$ ), which was used by four ambulant patients, and a staminal treatment, which was received by one nonambulant patient

${ }^{c}$ Includes costs related to formal caregivers, social institutions, and transport services (ambulances and adapted vehicle transport)

Furthermore, as illustrated in Fig. 1, the majority of annualized lifetime disease costs appear to be larger around the time ambulation is lost (10 years of age). Loss of ambulation marks a critical milestone in disease progression, not only because of its direct clinical implications but also because of the higher economic burden it entails. Around this time, families may be confronted with a greater need to pursue one-off acquisitions, such as wheelchairs or even making house and/or car adaptations which, given the short time period between diagnosis and the moment of the interview, led annualized lifetime disease costs to reach a high level far above $€ 64,500$ per year.

Although lifetime annualized costs continued to be substantial across the late teens and adulthood, maintaining a level far above those observed in ambulant patients, they trended towards a lower level of $€ 50,000$ per year among older patients. This can be explained by the high discounting in one-off acquisition costs applied to older patients, resulting from the wider time gap between diagnosis and the moment of the interview, as well as the lower frequency of new acquisitions later in life. Interestingly, lifetime annualized costs appeared to increase again after the age of 30 years. This may be a reflection of the greater end-of-life medical costs expected to occur around this time. However, it is difficult to draw any definite conclusion because of the small number of patients in the group aged 30-40 years.

Younger patients who were still ambulant at the time of the interview had a mean annualized lifetime cost of less than $€ 25,000$. This cost later appeared to decline as age/ disease progression increased, a similar trend to that identified by Schreiber-Katz et al. [6], where patients in the clinical severity stage II (late ambulatory with high impairment) appeared to have higher annual costs than those in stage III (early nonambulatory). Younger patients with DMD, even in the absence of any significant symptoms, naturally require more care. This may make it difficult for caregivers to estimate the amount of informal care or work productivity impact that can be directly attributable to DMD, resulting in its overestimation. Entry into primary school around the age of 6 years may also help free up caregiver time, reducing caregiver burden. 
Fig. 1 Observed and estimated annualized lifetime cost $(€)$ by age of patient at interview. Age is used as a proxy of disease progression. Blue and red curves are the generalized additive model fitted for nonambulant and ambulant patients, respectively, and the shaded section represents the $95 \%$ confidence intervals for the mean curve estimates

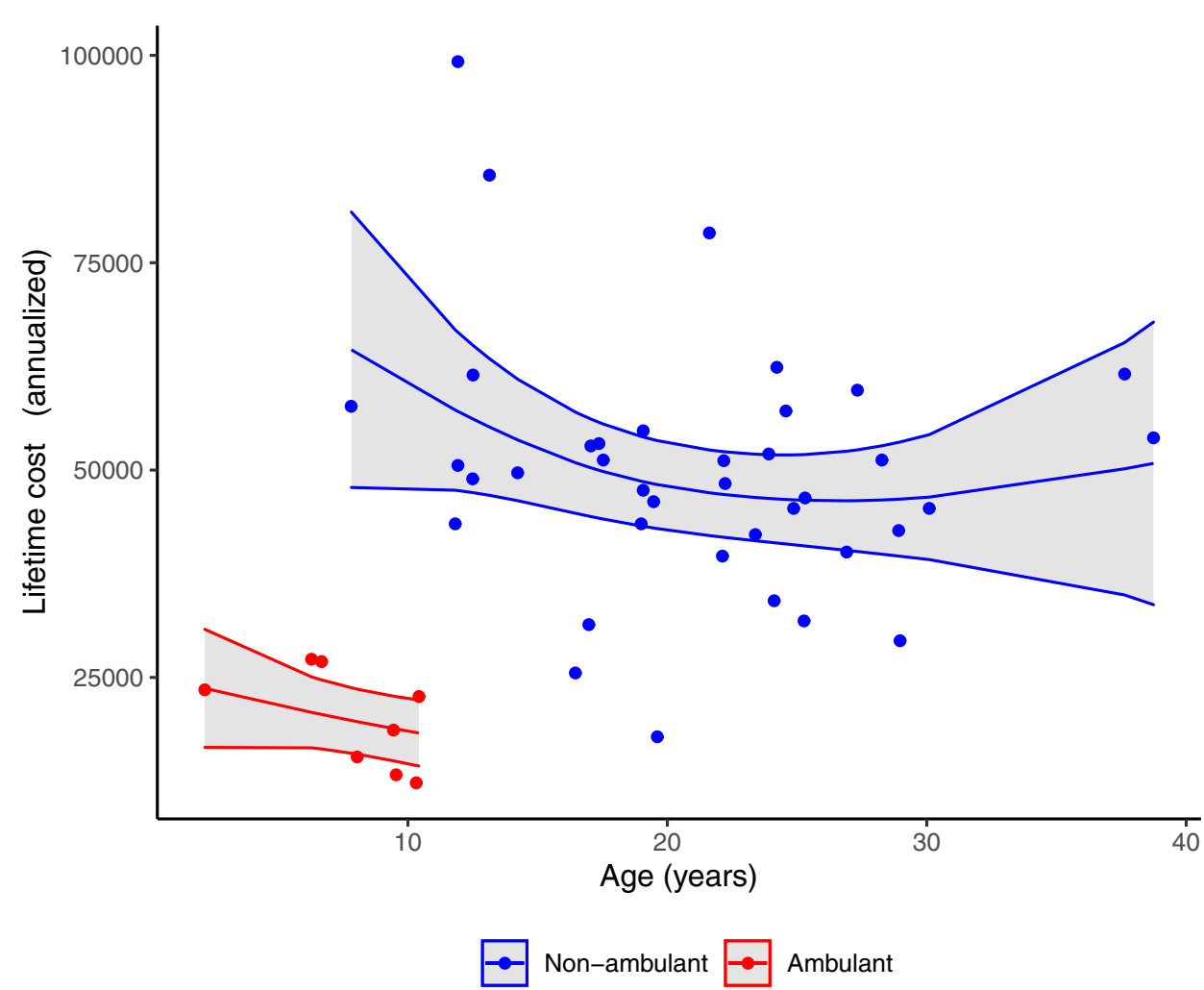

Differences in setting, costing categorization, and methodology made it challenging to compare DMD costs across different publications. Nevertheless, the results in this study appear to be largely consistent with those of other COI studies [6-8]. First, studies show a trend towards higher costs in patients with greater disease progression, often defined according to ambulatory status. However, one important distinction is that our analysis suggests that lifetime annualized costs are actually larger for nonambulant patients in their early teens, soon after ambulation is lost, than for both younger ambulant patients and older nonambulant patients.

Second, in Portugal, as in other European countries, direct medical costs appear to be substantially lower than both direct nonmedical and indirect costs. The question remains as to which of the latter two costs categories is the main cost driver. According to our analysis, as well as those of Cavazza et al. [7] and Landfeldt et al. [8], direct nonmedical costs appear to be more influential across European countries, but there are some exceptions, for example in Italy [8] or in ambulant patients in Germany, according to SchreiberKatz et al. [6]. Although this may be due to country-specific differences, other factors, such as cost methodology, may also have played an important role.

Although the DMD costs estimated in this study were substantial, they still underestimate the true economic cost of the disease. The interview-based and retrospective design of this study made it difficult to capture all relevant direct medical costs, for example, end-of-life costs expected to occur at the end of the nonambulant stage. This was a common issue across similar publications [6-8] and could be solved by future studies using hospital records, which could potentially capture most of these costs.

Informal care and indirect costs may also have been undervalued because we excluded the contribution of other relevant family members, who are also likely to be affected by the patient's condition. We were also unable to include potential patient indirect costs. From a technical standpoint, it would require a number of assumptions, such as assuming a mean starting age of employment for these patients had they not been affected by DMD.

One limitation of this study relates to a possible referral bias because patient identification and recruitment was conditional on their membership in the APN. Even though APN is a nationwide association, membership is voluntary and grants access to a wide range of services (e.g., rehabilitation care), making it more appealing to patients with a more severe clinical presentation. This may explain the small number of ambulant patients identified for this study $(n=8)$ which, in itself, represents another limitation. Including more ambulant patients is always going to be a challenge given the small number of confirmed cases of 
DMD in Portugal (142 according to one estimate [30]), the rapid progression of the disease, and the difficulties of establishing an early diagnosis while patients are still ambulant. A third limitation involves the recall period used. To limit the risk of memory bias, most items pertaining to past resource consumption and costs were restricted to a recall period of up to 6 months. However, this short recall period may have led some relevant seasonal data to be neglected from this analysis, for example, related to acute infections occurring during the winter months. To limit the impact of this, data concerning one-off acquisition items (medical devices, DMD-related household expenses, and surgeries) were captured over the patient's entire lifetime. Although this might have increased the risk of memory bias, we believe that the benefits of including past resource consumption that would otherwise be underreported if limited to a 6-month recall period, largely outweighed any potential downsides.

A major strength of this study relates to the data collection methodology. Face-to-face interviews using a semistructured questionnaire allowed for a more condensed and flexible data collection while also reducing the risk of respondents misinterpreting questions. Overall, this made data collection more robust, at least when compared with alternative methods such as telephone or mail surveys or using data from a national registry.

Our results highlight the economic burden of DMD, further reinforcing the potential clinical and economic benefits associated with delaying disease progression. Disease costs during the nonambulant stage were substantial and were especially high around the time ambulation was lost. Given the current unmet treatment needs, it is crucial to weigh the potential benefits of therapeutic innovations against the expected increase in direct medical costs.

\section{Conclusion}

Our analysis supports the thesis that disease progression contributes to an increase in overall DMD costs. Therefore, the availability of new therapeutic options that can delay disease progression, especially loss of ambulation, may prove to be highly beneficial for not only patients with DMD but also their families and society.

Supplementary Information The online version contains supplementary material available at https://doi.org/10.1007/s41669-021-00303-5.

Acknowledgements The authors thank the Portuguese Neuromuscular Patients Association for assistance in validating the health resource questionnaire and in identifying patients with DMD.

\section{Declarations}

Conflict of Interest PL, VA, MM, SM, RA, JA, BV, and JF are employees of Exigo Consultores. Exigo Consultores provides consulting services to PTC Therapeutics under a fee-for-services contract. KB, $\mathrm{HC}$, and IBOZ are employees of PTC Therapeutics.

Funding This study was funded by PTC Therapeutics. Authors affiliated with Exigo are employees of an independent consulting firm and maintained independent scientific control over the study, including data analysis and interpretation of final results.

Ethics Approval COIDUCH was developed following a direct request by the National Authority of Medicines and Health Products (INFARMED) after the reimbursement decision for Translarna ${ }^{\circledR}$ in Portugal. Following this request, the study protocol was developed and sent to INFARMED, which validated it. Note that, since 2014, the Ethics Committee for Clinical Investigation (CEIC) has been working with INFARMED to approve nationwide studies whenever a local ethics committee for health (CES) has not been designated for the purpose. This was the case with COIDUCH, as it did not involve any hospital (where CES are often located). Ethical principles and good clinical research practices guided the execution of this study.

Consent to Participate Prior written informed consent was obtained from participants. The anonymity of the participants was guaranteed. All personal data were managed according to the General Data Protection Regulation.

Consent for Publication Not applicable as the manuscript does not contain any personal data related to an identified or identifiable participant.

Availability of Data and Materials An Excel database was developed in which to register the original data from the questionnaire, and the software $\mathrm{R}$ was used to analyze the data. All aggregate data generated or analysed are included in this published article. No individual data are available to protect the anonymity of individual patients.

Code availability Not applicable.

Author Contributions PL and MM designed the study, collected the data, and drafted the manuscript. VA designed the study, analysed the data, and drafted the manuscript. SM and JA collected the data. JF and $\mathrm{BV}$ designed the study and contributed to the interpretation of the data. $\mathrm{KB}, \mathrm{HC}$, and IBOZ supported the planning phase of the interviews. All authors read and approved the final manuscript.

Open Access This article is licensed under a Creative Commons Attribution-NonCommercial 4.0 International License, which permits any non-commercial use, sharing, adaptation, distribution and reproduction in any medium or format, as long as you give appropriate credit to the original author(s) and the source, provide a link to the Creative Commons licence, and indicate if changes were made. The images or other third party material in this article are included in the article's Creative Commons licence, unless indicated otherwise in a credit line to the material. If material is not included in the article's Creative Commons licence and your intended use is not permitted by statutory regulation or exceeds the permitted use, you will need to obtain permission directly from the copyright holder. To view a copy of this licence, visit http://creativecommons.org/licenses/by-nc/4.0/. 


\section{References}

1. Crisafulli S, Sultana J, Fontana A, Salvo F, Messina S, Trifirò G. Global epidemiology of Duchenne muscular dystrophy: an updated systematic review and meta-analysis. Orphanet J Rare Dis. 2020;15(1): 141 .

2. Birnkrant DJ, Bushby K, Bann CM, Apkon SD, Blackwell A, Brumbaugh D, et al. Diagnosis and management of Duchenne muscular dystrophy, part 1: diagnosis, and neuromuscular, rehabilitation, endocrine, and gastrointestinal and nutritional management. Lancet Neurol. 2018;17(3):251-67.

3. Ryder S, Leadley RM, Armstrong N, Westwood M, de Kock S, Butt $\mathrm{T}$, et al. The burden, epidemiology, costs and treatment for Duchenne muscular dystrophy: an evidence review. Orphanet J Rare Dis. 2017;12(1):79.

4. Landfeldt E, Thompson R, Sejersen T, McMillan HJ, Kirschner $\mathrm{J}$, Lochmüller H. Life expectancy at birth in Duchenne muscular dystrophy: a systematic review and meta-analysis. Eur J Epidemiol. 2020;35(7):643-53.

5. Connolly AM, Zaidman CM, Golumbek PT, Cradock MM, Flanigan KM, Kuntz NL, et al. Twice-weekly glucocorticosteroids in infants and young boys with Duchenne muscular dystrophy. Muscle Nerve. 2019;59(6):650-7.

6. Schreiber-Katz O, Klug C, Thiele S, Schorling E, Zowe J, Reilich $\mathrm{P}$, et al. Comparative cost of illness analysis and assessment of health care burden of Duchenne and Becker muscular dystrophies in Germany. Orphanet J Rare Dis. 2014;9:210.

7. Cavazza M, Kodra Y, Armeni P, De Santis M, Lopez-Bastida J, Linertova R, et al. Social/economic costs and health-related quality of life in patients with Duchenne muscular dystrophy in Europe. Eur J Health Econ HEPAC. 2016;17(Suppl 1):19-29.

8. Landfeldt E, Lindgren P, Bell CF, Schmitt C, Guglieri M, Straub $\mathrm{V}$, et al. The burden of Duchenne muscular dystrophy: an international, cross-sectional study. Neurology. 2014;83(6):529-36.

9. Reilly MC, Zbrozek AS, Dukes EM. The validity and reproducibility of a work productivity and activity impairment instrument. Pharmacoeconomics. 1993;4(5):353-65.

10. Instituto Nacional de Estatística 2020. 2020. https://www.ine.pt/ xportal/xmain?xpgid=ine_main\& $x$ pid=INE.

11. Portaria no. $254 / 2018$ de 7 de setembro. Diário da República, 1 . $^{\mathrm{a}}$ série-No. 173-7 de setembro de 2018. 2018.

12. Portaria no. $207 / 2017$ de 11 de julho. Diário da República, $1 .^{\mathrm{a}}$ série-No. 132-11 de julho de 2017. 2017.

13. IP ACdSdS. Termos de Referência para contratualização de cuidados de saúde no SNS para 2019. 2019.

14. Infomed. Base de dados de medicamentos. 2021. http://app7.infar med.pt/infomed/pesquisa.php.

15. Base.gov. Contratos públicos online. 2021. http://www.base.gov. $\mathrm{pt} /$ Base/pt/Homepage.

16. Koopmanschap MA, van Exel JN, van den Berg B, Brouwer WB. An overview of methods and applications to value informal care in economic evaluations of healthcare. Pharmacoeconomics. 2008;26(4):269-80.
17. Zweifel P, Breyer F. Health Economics. Oxford: Oxford University Press I; 1997.

18. INdEI. Ganho médio mensal $(€)$ por Localização geográfica (NUTS-2013), Sexo e Grupo etário; Anual 2019. 2019. https:// www.ine.pt/xportal/xmain?xpid=INE\&xpgid=ine_indicadores\& indOcorrCod $=0006914 \&$ contexto $=$ bd $\&$ selTab $=$ tab2 $\&$ xlang $=$ pt.

19. PP. Guia Fiscal 2017-Segurança Social. 2017. https://www.pwc.

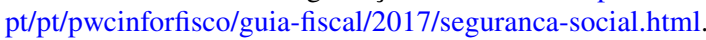

20. INdEI. Duração semanal efectiva de trabalho (Série 2011—h) da população empregada por Local de residência (NUTS-2013), Sexo e Sector de actividade económica (CAE Rev. 3); Anual 2019. 2019. https://www.ine.pt/xportal/xmain?xpid=INE\&xpgid=ine indicadores $\&$ indOcorrCod $=0006181 \&$ contexto $=$ bd $\&$ selTab $=$ tab2.

21. da Silva TD, Massetti T, Crocetta TB, de Mello Monteiro CB, Carll A, Vanderlei LCM, et al. Heart rate variability and cardiopulmonary dysfunction in patients with duchenne muscular dystrophy: a systematic review. Pediatr Cardiol. 2018;39(5):869-83.

22. de Carvalho EV, Hukuda ME, Escorcio R, Voos MC, Caromano FA. Development and reliability of the functional evaluation scale for Duchenne Muscular Dystrophy, Gait domain: a pilot study. Physiother Res Int. 2015;20(3):135-46.

23. Tandon A, Villa CR, Hor KN, Jefferies JL, Gao Z, Towbin JA, et al. Myocardial fibrosis burden predicts left ventricular ejection fraction and Is associated with age and steroid treatment duration in Duchenne Muscular Dystrophy. J Am Heart Assoc. 2015;4(4):e001338.

24. Parreira SLS, Resende MBD, Zanoteli E, Carvalho MS, Marie SK, Reed UC. Comparison of motor strength and function in patients with Duchenne muscular dystrophy with or without steroid therapy. Arq Neuropsiquiatr. 2010;68:683-8.

25. Jung I-Y, Chae JH, Park SK, Kim JH, Kim JY, Kim SJ, et al. The correlation analysis of functional factors and age with duchenne muscular dystrophy. Ann Rehabil Med. 2012;36(1):22-32.

26. Fischmann A, Hafner P, Gloor M, Schmid M, Klein A, Pohlman U, et al. Quantitative MRI and loss of free ambulation in Duchenne muscular dystrophy. J Neurol. 2013;260(4):969-74.

27. Mazzone E, Martinelli D, Berardinelli A, Messina S, D'Amico A, Vasco G, et al. North Star Ambulatory Assessment, 6-minute walk test and timed items in ambulant boys with Duchenne muscular dystrophy. Neuromuscul Disord. 2010;20(11):712-6.

28. Wood SN. Generalized additive models: an introduction with R. Boca Raton: CRC Press; 2017.

29. R Core Team. A Language and Environment for Statistical Computing. Vienna, Austria: R Foundation for Statistical Computing; 2019.

30. Garrido C, Palavra F, Cardoso M, Sousa A, Rocha R, Alves D, et al. Duchenne Muscular Dystrophy-Clinical: P. 16Epidemiology, clinical and genetic features of Duchenne disease in Portugal: a multicentre retrospective study. Neuromuscul Disord. 2018;28:S36. 